\title{
Association Between the Hospital Readmissions Reduction Program and Heart Failure Subtype Readmissions and Mortality in the USA
}

The Hospital Readmission Reduction Program (HRRP) in the USA sought to penalise hospitals with readmissions above the national average, and heart failure (HF) has been a leading contributor to these HRRP penalties. However, the effectiveness of this strategy has recently been questioned. Therefore, my choice for the Editor's Pick in this issue is the fascinating and timely study by Sheikh et al., which examines the effect of the HRRP on HF mortality and readmissions over time using large national datasets and is the first to analyse based on HF subtypes. This article reports novel findings that advance our understanding of HF and is a valuable addition to the literature.

\section{Çetin Erol}

Ankara University, Turkey
Authors:
*Wasiq Sheikh, ${ }^{1}$ Malik Bilal Ahmed, ${ }^{2}$ Anshul Parulkar, ${ }^{1}$ Tamara Lhungay, Esseim Sharma, ${ }^{1}$ Kevin Kennedy, ${ }^{3}$ Zara Ahmed, ${ }^{4}$ Fabio Lima, ${ }^{1}$ Herbert Aronow, ${ }^{1}$ Antony $\mathrm{Chu}^{1}$
1. Lifespan Cardiovascular Institute, Brown University, Providence, Rhode Island, USA
2. Cardiovascular Center, Tufts Medical Center, Boston, Massachusetts, USA
3. Department of Biostatistics, St. Luke's Mid-America Heart Institute, Kansas City, Missouri, USA
4. Department of Mathematics, University of Alabama at Birmingham, Alabama, USA
*Correspondence to wsheikh92@gmail.com

Disclosure:

The authors have declared no conflicts of interest.

Received:

18.12.20

Accepted:

09.04 .21

Keywords:

Heart failure with preserved ejection fraction (HFpEF), heart failure with reduced ejection fraction (HFrEF), Hospital Readmission Reduction Program (HRRP), mortality, readmissions.

Citation:

EMJ Cardiol. 2021;9[1]:56-66.

\section{Abstract}

Background: The Hospital Readmission Reduction Program (HRRP) sought to reduce readmissions by penalising centres with readmissions above the national average, and heart failure (HF) is the leading driver of the readmission penalty. Recent Medicare analyses question the effectiveness of this strategy. This study evaluated the efficacy of HRRP by utilising large national datasets and is the first to analyse based on heart failure subtypes. 
Methods: Aggregate data was used from the National Inpatient Sample (NIS) to study mortality and the National Readmissions Database (NRD) to study readmissions. Both included all payertypes and were stratified by heart failure subtype and time (pre- and post-HRRP implementation).

Results: Patients with HF with preserved ejection fraction (HFpEF) tended to be older females with a higher proportion of comorbidities compared to patients with HF with reduced ejection fraction (HFrEF). In the post-HRRP period, readmission rates decreased for HFrEF (21.4\% versus $22.3 \%$, $\mathrm{p}<0.001$ ) and HFpEF (21.2\% versus $22.4 \%, \mathrm{p}<0.001$ ); readmission rates for the two subtypes were not statistically different compared to the other. Post-HRRP, inpatient mortality was consistent for HFrEF (2.8\% versus 2.8\%, $\mathrm{p}=0.087$ ), but decreased for HFpEF (2.4\% versus $2.5 \%, p=0.029$ ). There were no significant differences noted in average length of stay. Patients with HFrEF were more frequently discharged to short-term hospitals or home with home healthcare, and patients with HFpEF were discharged to skilled nursing facilities more often. Estimated inpatient costs decreased in both subtypes post-HRRP, but readmission costs were higher for HFrEF.

Conclusions: This study suggests that HRRP was associated with minimal change in readmission and inpatient mortality.

\section{INTRODUCTION}

\section{METHODS}

The Hospital Readmissions Reduction Program (HRRP) was designed to penalise hospitals for excess readmission ratios in six categories, including heart failure (HF). ${ }^{1} \mathrm{HF}$ has been a major contributor to these HRRP penalties. ${ }^{2-4}$ While initial data have indicated a decline in readmission rates following initiation of the HRRP in 2012,5,6 Medicare data suggest that the 30-day postdischarge mortality following HF hospitalisations has increased. 7,8 These findings suggest that an inverse relationship exists between readmission rates and mortality. ${ }^{9-11}$

Most studies relating the HRRP to HF readmission and mortality rates make no distinction between HF with preserved ejection fraction (HFpEF) and reduced ejection fraction (HFrEF) subtypes, despite the fact that HFpEF represents nearly half of all heart failure admissions. ${ }^{12-16}$ However, it is clear that the HF subtypes affect distinctly different populations, with HFpEF occurring predominantly in older females and patients with more comorbidities. ${ }^{17,18}$ Due to the different populations and fundamental pathophysiology, outcomes should differ between the HF subtypes. This study sought to examine the effect of HRRP implementation on HF mortality and readmissions over time using the National Readmissions Database (NRD) and the National Inpatient Sample (NIS), stratified by HF subtype and time period, and divided into pre- and postHRRP implementation.

\section{Data Source}

This study was deemed exempt by the Institutional Review Board at Rhode Island Hospital, Providence, Rhode Island, USA. Data were obtained from two data sets: the NRD and the NIS. The NRD is a publicly accessible database that collects clinical, non-clinical, and procedural data for roughly 36 million yearly discharges, tracking both payers and the uninsured. The data are drawn from state-specific inpatient databases in order to generate approximations of national readmissions. The NRD database was created from 27 geographically dispersed states with verifiable patient linkage numbers, which were subsequently utilised to track patients across hospitals within a state while maintaining privacy through de-identification of patient information. The NIS is the largest publicly available, all-payer, inpatient healthcare database in the USA, sampled from all inpatient data contributed to the federally funded Healthcare Cost and Utilization Project (HCUP), approximating a 20\% stratified sample of all discharges from community hospitals in the USA.

\section{Study Population}

A total of 4,483,987 patient records were identified using the NIS and 2,790,873 patient records were identified using the NRD. 
Sample weights were applied in the analysis to estimate the overall national cohort. Of the patient records identified through the NIS, 2,596,442 were pre-HRRP, of which 1,409,597 were identified as HFrEF and 1,186,845 as HFpEF; and 1,887,595 were post-HRRP, of which 1,012,430 were identified as HFrEF and 875,115 as HFpEF. Similarly, of the patients identified through the NRD, 1,271,532 were pre-HRRP, of which 713,796 were identified as HFrEF and 557,736 as HFpEF; and 1,519,341 were post-HRRP, of which 802,254 were identified as HFrEF and 717,087 as HFpEF. The International Classification of Diseases $9^{\text {th }}$ Revision (ICD-9) codes utilised in the analysis are as follows: 438.20 , systolic HF, unspecified; 428.21, acute systolic HF; 428.22, chronic systolic HF, 428.23, acute-on-chronic systolic $\mathrm{HF}$; 428.30, diastolic HF, unspecified; 428.31, acute diastolic HF; 428.32, chronic diastolic $\mathrm{HF}$; and 428.33, acute-on-chronic diastolic HF.

Table 1: Demographic, clinical, and hospital characteristics by heart failure subtype pre- and post-Hospital Readmissions Reduction Program (HRRP) in the Nationwide Readmissions Database (NRD).

\begin{tabular}{|c|c|c|c|c|c|}
\hline \multirow[t]{3}{*}{ NRD } & \multicolumn{2}{|l|}{ Pre-HRRP } & \multicolumn{2}{|l|}{ Post-HRRP } & \multirow[t]{3}{*}{$p$ value } \\
\hline & HFrEF & HFpEF & HFrEF & HFpEF & \\
\hline & $n=713,796$ & $n=557,736$ & $n=802,254$ & $n=717,087$ & \\
\hline $\begin{array}{l}\text { Age of admission } \\
\text { (years) }\end{array}$ & $70.6 \pm 14.6$ & $75.6 \pm 12.6$ & $70.1 \pm 14.6$ & $75.5 \pm 12.7$ & $<0.0010 .038$ \\
\hline $\begin{array}{l}\text { Proportion of } \\
\text { females }\end{array}$ & $40.1 \%$ & $64.2 \%$ & $38.8 \%$ & $62.4 \%$ & $\begin{array}{l}<0.001 \\
<0.001\end{array}$ \\
\hline \multicolumn{6}{|l|}{ Expected payor } \\
\hline Medicare & $72.7 \%$ & $82.8 \%$ & $71.6 \%$ & $83.2 \%$ & $\begin{array}{l}<0.001 \\
<0.001\end{array}$ \\
\hline Private insurance & $12.3 \%$ & $8.7 \%$ & $11.8 \%$ & $8.1 \%$ & $\begin{array}{l}<0.001 \\
<0.001\end{array}$ \\
\hline Medicaid & $9.0 \%$ & $5.5 \%$ & $10.5 \%$ & $5.7 \%$ & $\begin{array}{l}<0.001 \\
<0.001\end{array}$ \\
\hline \multicolumn{6}{|c|}{ Total proportion of cases } \\
\hline $\begin{array}{l}\text { Government } \\
\text { hospitals }\end{array}$ & $12.5 \%$ & $10.6 \%$ & $11.6 \%$ & $9.5 \%$ & $\begin{array}{l}<0.001 \\
<0.001\end{array}$ \\
\hline $\begin{array}{l}\text { Non-profit private } \\
\text { hospitals }\end{array}$ & $73.9 \%$ & $75.1 \%$ & $73.6 \%$ & $76.6 \%$ & $\begin{array}{l}<0.001 \\
<0.001\end{array}$ \\
\hline $\begin{array}{l}\text { For-profit } \\
\text { hospitals }\end{array}$ & $13.6 \%$ & $14.4 \%$ & $14.2 \%$ & $14.0 \%$ & $\begin{array}{l}<0.001 \\
<0.001\end{array}$ \\
\hline $\begin{array}{l}\text { Metropolitan non- } \\
\text { teaching hospitals }\end{array}$ & $40.2 \%$ & $43.3 \%$ & $31.9 \%$ & $34.2 \%$ & $\begin{array}{l}<0.001 \\
<0.001\end{array}$ \\
\hline $\begin{array}{l}\text { Metropolitan } \\
\text { teaching hospitals }\end{array}$ & $47.5 \%$ & $44.7 \%$ & $56.7 \%$ & $54.1 \%$ & $\begin{array}{l}<0.001 \\
<0.001\end{array}$ \\
\hline $\begin{array}{l}\text { Non-metropolitan } \\
\text { hospitals }\end{array}$ & $12.2 \%$ & $12.0 \%$ & $11.4 \%$ & $11.8 \%$ & $\begin{array}{l}<0.001 \\
<0.001\end{array}$ \\
\hline \multicolumn{6}{|l|}{ Chronic conditions } \\
\hline $\begin{array}{l}\text { Peripheral } \\
\text { vascular disorders }\end{array}$ & $11.8 \%$ & $12.2 \%$ & $12.2 \%$ & $12.8 \%$ & $\begin{array}{l}<0.001 \\
<0.001\end{array}$ \\
\hline $\begin{array}{l}\text { Chronic pulmonary } \\
\text { disease }\end{array}$ & $33.5 \%$ & $40.6 \%$ & $34.8 \%$ & $42.3 \%$ & $\begin{array}{l}<0.001 \\
<0.001\end{array}$ \\
\hline
\end{tabular}


Table 1 continued.

\begin{tabular}{|l|l|l|l|l|l|}
\hline $\begin{array}{l}\text { Diabetes with } \\
\text { complications }\end{array}$ & $9.1 \%$ & $12.2 \%$ & $10.0 \%$ & $13.1 \%$ & $\begin{array}{l}<0.001 \\
<0.001\end{array}$ \\
\hline Liver disease & $2.6 \%$ & $2.6 \%$ & $3.2 \%$ & $3.1 \%$ & $\begin{array}{l}<0.001 \\
<0.001\end{array}$ \\
\hline Obesity & $14.2 \%$ & $21.2 \%$ & $17.8 \%$ & $26.9 \%$ & $\begin{array}{l}<0.001 \\
<0.001\end{array}$ \\
\hline Renal failure & $39.2 \%$ & $42.3 \%$ & $40.7 \%$ & $44.6 \%$ & $\begin{array}{l}<0.001 \\
<0.001\end{array}$ \\
\hline Hypertension & $72.8 \%$ & $78.8 \%$ & $75.7 \%$ & $81.1 \%$ & $\begin{array}{l}<0.001 \\
<0.001\end{array}$ \\
\hline Readmission rate & $21.8 \%$ & $22.1 \%$ & $21.0 \%$ & $21.0 \%$ & $\begin{array}{l}<0.001 \\
<0.001\end{array}$ \\
\hline $\begin{array}{l}\text { Length of stay } \\
\text { (days) }\end{array}$ & $5.4 \pm 6.1$ & $5.4 \pm 5.3$ & $5.5 \pm 6.3$ & $5.3 \pm 5.0$ & $\begin{array}{l}0.811 \\
<0.001\end{array}$ \\
\hline $\begin{array}{l}\text { Cost of } \\
\text { readmission (USD) }\end{array}$ & $14,434 \pm 25,809$ & $14,111 \pm 21,037$ & $15,086 \pm 29,233$ & $13,935 \pm 21,350$ & $\begin{array}{l}<0.001 \\
0.365\end{array}$ \\
\hline $\begin{array}{l}\text { Cost of index } \\
\text { admission (USD) }\end{array}$ & 7,489 & 7,418 & 7,469 & 7,454 & $\begin{array}{l}0.216 \\
<0.001\end{array}$ \\
\hline $\begin{array}{l}\text { Median time } \\
\text { to readmission } \\
\text { (days) }\end{array}$ & $5-20$ & $5-20$ & $6-20$ & $6-20$ & $\begin{array}{l}<0.001 \\
<0.001\end{array}$ \\
\hline
\end{tabular}

HFpEF: heart failure with preserved ejection fraction; HFrEF: heart failure with reduced ejection fraction; HRRP: Hospital Readmissions Reduction Program; NRD: Nationwide Readmissions Database.

\section{Statistical Analysis}

Data were retrospectively reviewed from all heart failure hospitalisations in the NIS to study mortality and in the NRD to study readmissions, stratified by time. The population was divided into two cohorts: preand post-HRRP. The NIS 'pre-HRRP' included $1^{\text {st }}$ January 2005 until $30^{\text {th }}$ September 2012, and 'post-HRRP' included $1^{\text {st }}$ October 2012 until $30^{\text {th }}$ September 2015. Similarly, the NRD was divided into 'pre-HRRP', from $1^{\text {st }}$ January 2010 until 30 th September 2012, and 'post-HRRP', from $1^{\text {st }}$ October 2012 until $30^{\text {th }}$ September 2015. Associated comorbid conditions, demographic data, disposition, and hospital type were also extrapolated and shown as mean \pm standard deviation for continuous and $\mathrm{n}$ (\%) for categorical data. For unadjusted comparisons, preand post-HRRP variables were compared using Student's t-test and chi-square test, as appropriate. Risk-standardised mortality and readmission rates along with 95\% confidence intervals were generated using SAS ${ }^{\circledR} 9.4$ (SAS; Cary, North Carolina, USA) for all analyses. A $p$ value of 0.05 indicated statistical significance.

\section{RESULTS}

\section{Nationwide Readmissions Database}

\section{Heart failure with reduced ejection fraction}

The total sample size for the pre- and post-HRRP periods were 713,796 and 802,254 , respectively. Demographic, clinical, and hospital data from the NRD stratified by HF subtype and the preand post-HRRP periods are shown in Table 1 . The post-HRRP period saw an increase in the number of chronic conditions $(2.8 \pm 1.2$ versus $2.9 \pm 1.2, p<0.001$ ). 
The post-HRRP period saw a reduction in readmission rate $(21.8 \%$ versus $21.0 \%, \mathrm{p}<0.001$ ). The cost of the index admission was not statistically different between both time periods; however, the readmission cost was statistically higher in the post-HRRP period $(14,434 \pm 25,809$ versus $15,086 \pm 29,233$ USD, $p<0.001)$. The median time to readmission was slightly higher in the post-HRRP group (5-20 days versus 6-20 days, $p<0.001$ ).

\section{Heart failure with preserved ejection fraction}

The total sample size for the pre- and post-HRRP periods were 557,736 and 717,087, respectively. There was a statistically significant decrease in the proportion of female HFpEF cases (64.2\% versus $62.4 \%, p<0.001$ ).
The readmission rate in the post-HRRP period was lower compared to pre-HRRP (22.1\% versus $21.0 \%$, $\mathrm{p}<0.001)$. The readmission length of stay was slightly lower in the post-HRRP period (5.4 \pm 5.3 versus $5.3 \pm 5.0$ days, $p<0.001)$. The cost of the index admission was higher in the post-HRRP period (7,418 versus 7,454 USD, $p<0.001$ ).

\section{Heart failure with reduced ejection fraction versus heart failure with preserved ejection fraction: pre-Hospital Readmissions Reduction Program}

On average, patients in the HFpEF group tended to be older $(p<0.001)$, and were more likely to be female $(p<0.001)$. The HFpEF group was more likely to have Medicare as the expected payor, whereas Medicaid and Private insurance were

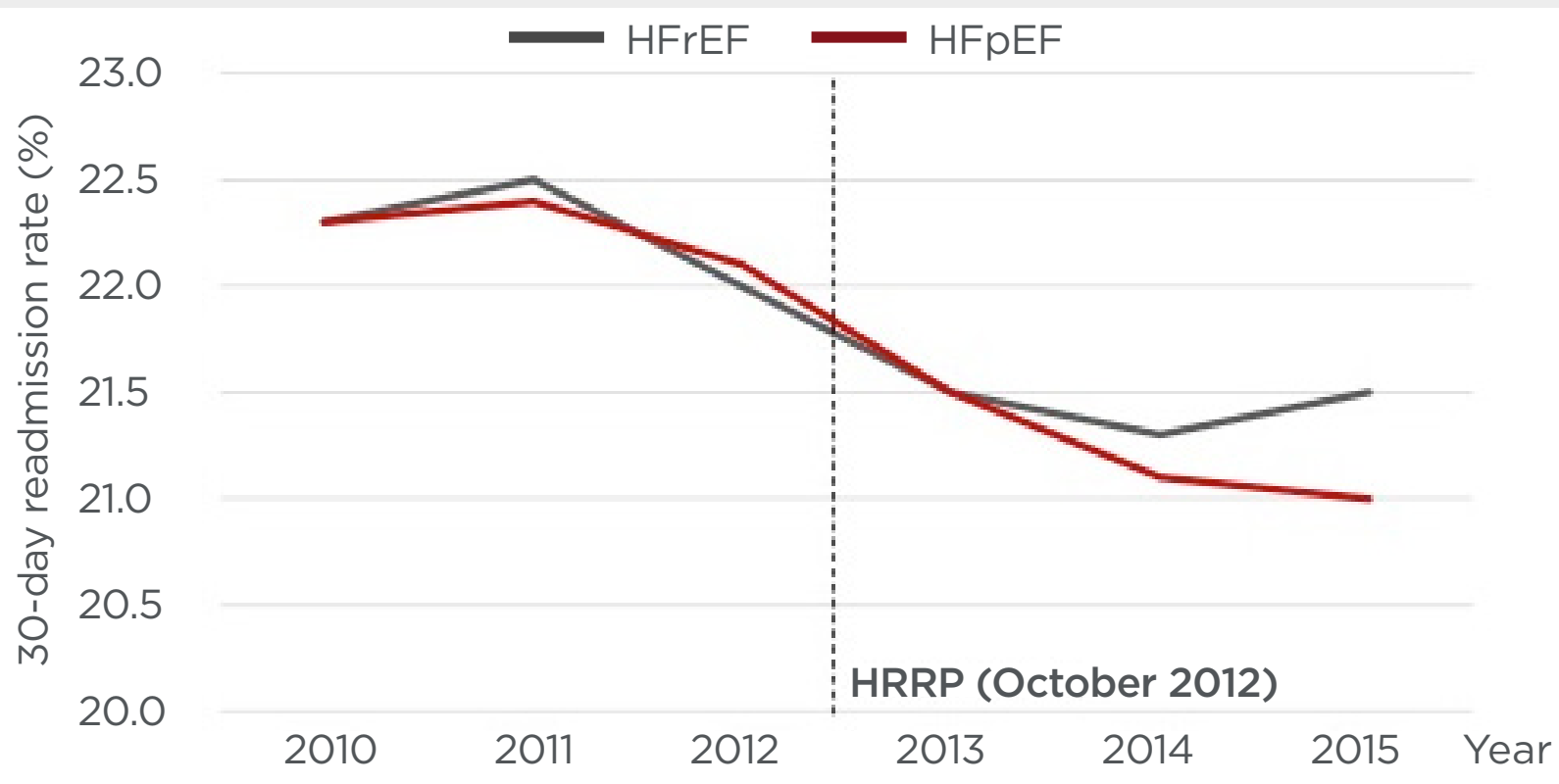

Figure 1: Thirty-day readmission rates before and after implementation of the Hospital Readmissions Reduction Program (HRRP).

HFpEF: heart failure with preserved ejection fraction; HFrEF: heart failure with reduced ejection fraction; HRRP: Hospital Readmissions Reduction Program.

more likely to be the payor for patients with HFrEF. Patients with HFpEF were more likely to be either at private non-profit or private for-profit hospitals, while patients with HFrEF were more likely to be in government-owned hospitals $(p<0.001)$. Of the Elixhauser comorbidities, patients with HFpEF tended to have a higher likelihood of having chronic lung disease, diabetes with chronic complications, renal failure, obesity, and hypertension.
The readmission rate pre-HRRP between HFpEF and HFrEF were not statistically different $(p=0.831)$. The cost of readmission and index admission was higher for patients with HFrEF $(p<0.001)$; however, the length of stay for patients with HFpEF was higher $(p=0.01)$. 
Table 2: Demographic, clinical, and hospital characteristics by heart failure subtype pre- and post-Hospital Readmissions Reduction Program (HRRP) in the National Inpatient Sample (NIS).

\begin{tabular}{|c|c|c|c|c|c|}
\hline \multirow[t]{3}{*}{ NIS } & \multicolumn{2}{|l|}{ Pre-HRRP } & \multicolumn{2}{|l|}{ Post-HRRP } & \multirow[t]{3}{*}{$p$ value } \\
\hline & HFrEF & HFpEF & HFrEF & HFpEF & \\
\hline & $n=713,796$ & $n=557,736$ & $\mathrm{n}=802,254$ & $n=717,087$ & \\
\hline $\begin{array}{l}\text { Age of admission } \\
\text { (years) }\end{array}$ & 70.9 & $75.68 \pm 13.14$ & 69.9 & $75.34 \pm 12.76$ & $\begin{array}{l}<0.001 \\
<0.001\end{array}$ \\
\hline $\begin{array}{l}\text { Proportion of } \\
\text { females }\end{array}$ & $40.1 \%$ & $64.8 \%$ & $38.1 \%$ & $62.8 \%$ & $\begin{array}{l}<0.001 \\
<0.001\end{array}$ \\
\hline \multicolumn{6}{|l|}{ Expected payor } \\
\hline Medicare & $10.8 \%$ & $80.7 \%$ & $8.7 \%$ & $81.5 \%$ & $\begin{array}{l}<0.001 \\
<0.001\end{array}$ \\
\hline Medicaid & $8.7 \%$ & $5.6 \%$ & $10.8 \%$ & $6.1 \%$ & $\begin{array}{l}<0.001 \\
<0.001 \\
\end{array}$ \\
\hline Private payer & $13.5 \%$ & $10.3 \%$ & $12.9 \%$ & $9.4 \%$ & $\begin{array}{l}<0.001 \\
<0.001\end{array}$ \\
\hline \multicolumn{6}{|c|}{ Proportion of cases by race } \\
\hline Caucasian & $67.2 \%$ & $72.6 \%$ & $65.1 \%$ & $73.9 \%$ & $\begin{array}{l}<0.001 \\
<0.001\end{array}$ \\
\hline African American & $21.5 \%$ & $6.7 \%$ & $22.5 \%$ & $6.5 \%$ & $\begin{array}{l}<0.001 \\
<0.001\end{array}$ \\
\hline Hispanic & $1.4 \%$ & $1.6 \%$ & $1.9 \%$ & $1.8 \%$ & $\begin{array}{l}<0.001 \\
<0.001\end{array}$ \\
\hline \multicolumn{6}{|c|}{ Total proportion of cases } \\
\hline $\begin{array}{l}\text { Rural non- } \\
\text { teaching hospitals }\end{array}$ & $12.0 \%$ & $11.9 \%$ & $10.9 \%$ & $11.6 \%$ & $\begin{array}{l}<0.001 \\
<0.001\end{array}$ \\
\hline $\begin{array}{l}\text { Urban non- } \\
\text { teaching hospitals }\end{array}$ & $40.9 \%$ & $43.6 \%$ & $32.0 \%$ & $33.8 \%$ & $\begin{array}{l}<0.001 \\
<0.001\end{array}$ \\
\hline Teaching hospitals & $47.1 \%$ & $44.6 \%$ & $57.1 \%$ & $54.6 \%$ & $\begin{array}{l}<0.001 \\
<0.001\end{array}$ \\
\hline \multicolumn{6}{|l|}{ Chronic conditions } \\
\hline $\begin{array}{l}\text { Iron deficiency } \\
\text { anaemia }\end{array}$ & $24.6 \%$ & $33.3 \%$ & $26.5 \%$ & $36.5 \%$ & $\begin{array}{l}<0.001 \\
<0.001\end{array}$ \\
\hline $\begin{array}{l}\text { Chronic } \\
\text { pulmonary } \\
\text { disease }\end{array}$ & $33.6 \%$ & $40.5 \%$ & $35.8 \%$ & $43.5 \%$ & $\begin{array}{l}<0.001 \\
<0.001\end{array}$ \\
\hline $\begin{array}{l}\text { Uncomplicated } \\
\text { diabetes }\end{array}$ & $33.1 \%$ & $33.7 \%$ & $35.0 \%$ & $34.8 \%$ & $\begin{array}{l}<0.001 \\
<0.001\end{array}$ \\
\hline Hypertension & $69.1 \%$ & $75.8 \%$ & $75.9 \%$ & $81.6 \%$ & $\begin{array}{l}<0.001 \\
<0.001\end{array}$ \\
\hline Liver disease & $2.5 \%$ & $2.4 \%$ & $3.5 \%$ & $3.3 \%$ & $\begin{array}{l}<0.001 \\
<0.001\end{array}$ \\
\hline Obesity & $12.5 \%$ & $19.1 \%$ & $17.6 \%$ & $26.9 \%$ & $\begin{array}{l}<0.001 \\
<0.001\end{array}$ \\
\hline $\begin{array}{l}\text { Peripheral } \\
\text { vascular disease }\end{array}$ & $11.6 \%$ & $11.6 \%$ & $12.9 \%$ & $13.0 \%$ & $\begin{array}{l}<0.001 \\
<0.001\end{array}$ \\
\hline Renal failure & $38.1 \%$ & $40.2 \%$ & $41.6 \%$ & $45.3 \%$ & $\begin{array}{l}<0.001 \\
<0.001\end{array}$ \\
\hline
\end{tabular}




\begin{tabular}{|l|l|l|l|l|l|}
\hline $\begin{array}{l}\text { Readmission } \\
\text { disposition }\end{array}$ & $55.0 \%$ & $47.1 \%$ & $53.4 \%$ & $44.2 \%$ & $\begin{array}{l}<0.001 \\
<0.001\end{array}$ \\
\hline Transfer to SNF & $16.9 \%$ & $24.2 \%$ & $16.7 \%$ & $24.7 \%$ & $\begin{array}{l}<0.001 \\
<0.001\end{array}$ \\
\hline $\begin{array}{l}\text { Transfer to short- } \\
\text { term hospital }\end{array}$ & $2.9 \%$ & $1.83 \%$ & $3.2 \%$ & $1.84 \%$ & $\begin{array}{l}<0.001 \\
<0.001\end{array}$ \\
\hline Transfer to HHC & $21.3 \%$ & $23.9 \%$ & $22.6 \%$ & $26.1 \%$ & $\begin{array}{l}<0.001 \\
<0.001\end{array}$ \\
\hline $\begin{array}{l}\text { Length of stay } \\
\text { (days) }\end{array}$ & $5.43 \pm 5.87$ & $5.37 \pm 5.09$ & $5.41 \pm 6.31$ & $5.23 \pm 4.93$ & $\begin{array}{l}0.305 \\
<0.001\end{array}$ \\
\hline $\begin{array}{l}\text { Estimated } \\
\text { inpatient cost } \\
\text { (USD) }\end{array}$ & $13,094 \pm 21,879$ & $10,657 \pm 13,221$ & $12,897 \pm 25,979$ & $10,251 \pm 13,099$ & $\begin{array}{l}<0.001 \\
<0.001\end{array}$ \\
\hline $\begin{array}{l}\text { Inpatient mortality } \\
\text { 2.8\% }\end{array}$ & $2.5 \%$ & & $2.8 \%$ & $2.4 \%$ & $\begin{array}{l}0.087 \\
<0.001\end{array}$ \\
\hline
\end{tabular}

HFpEF: heart failure with preserved ejection fraction; HFrEF: heart failure with reduced ejection fraction; HHC: home healthcare; HRRP: Hospital Readmissions Reduction Program; NIS: National Inpatient Sample; SNF: skilled nursing facility.

\section{Heart failure with reduced ejection failure versus heart failure with preserved ejection fraction: post-Hospital Readmissions Reduction Program}

Post-HRRP was similar to pre-HRRP, except post-HRRP saw a higher proportion of HFrEF cases in government-owned and private forprofit hospitals, whereas HFpEF had a higher proportion of private non-profit in the post-HRRP period. In the post-HRRP period, patients with HFpEF were more likely to be in metropolitan non-teaching and non-metropolitan hospitals compared to patients with HFrEF, who tended to be in metropolitan teaching hospitals. In the post-HRRP period, patients with HFpEF tended to have an increase in the same comorbidities as pre-HRRP, plus iron deficiency anaemia.

The readmission cost was higher for HFrEF $(p<0.001)$, as was the cost of the index admission $(p<0.001)$. Figure 1 displays the year-by-year trend of readmission for both subtypes.

\section{National Inpatient Sample}

\section{Heart failure with reduced ejection fraction}

The total sample size for pre-HRRP was $1,409,597$ and 1,012,430 for post-HRRP. Demographic, clinical, and hospital data from the NIS stratified by HF subtype and the pre- and post-HRRP periods are shown in Table 2. Nearly all of the Elixhauser comorbidity measures were increased in the post-HRRP cohort.

The post-HRRP saw a decrease in routine disposition (55.0-53.4\%, $\mathrm{p}<0.001$ ) and transfers to skilled nursing facilities (SNF) (16.9-16.7\%, $\mathrm{p}<0.001$ ), but saw increases in transfers to short-term hospitals (2.9-3.2\%, $\mathrm{p}<0.001)$ and HHC (21.3-22.6\%, $p<0.001)$. The estimated inpatient cost for HfrEF decreased in the postHRRP period $(13,094 \pm 21,879-12,897 \pm 25,980$ USD, $p=0.004$ ).

\section{Heart failure with preserved ejection fraction}

The total sample size was $1,186,845$ for the pre-HRRP period and 875,115 for the postHRRP period. The post-HRRP period had a statistically significant annual increase of HfpEF cases. Nearly all of the Agency for Healthcare Research and Quality (AHRQ) comorbidity measures were increased in the post-HRRP cohort.

There was a slightly shorter length of stay post-HRRP for patients with HfpEF (5.37 \pm 5.09 $5.23 \pm 4.93$ days, $p<0.001)$. The post-HRRP period saw decreases in routine disposition (47.1-44.2\%, $p<0.001)$ but increases in transfers 
to SNFs (24.2-24.7\%, $\mathrm{p}<0.001)$ and a slight increase in transfers to short-term hospitals (1.83-1.84, $\mathrm{p}<0.001)$. The inpatient mortality for HfpEF had a statistically significant decrease in the post-HRRP period (2.5-2.4\%, $p=0.029$ ). Overall, the average cost of hospitalisation for HFpEF decreased $(10,657 \pm 13,222-10,252 \pm 13,099$ USD, $p<0.001$ ).

\section{Heart failure with reduced ejection fraction versus heart failure with preserved ejection fraction: pre-Hospital Readmissions Reduction Program}

Comparatively, HFrEF had a higher yearly proportion of cases during the pre-HRRP period. The average age at admission for HFpEF was higher compared to HFrEF $(75.68 \pm 13.14$ versus 70.89 $14.70, p<0.001)$. Overall, HFpEF was higher in Caucasian patients $(72.67 \%$ versus $67.2 \%$, $\mathrm{p}<0.001$ ), while African American and Hispanic patients had higher HFrEF rates (21.5\% versus $16.5 \%$, $\mathrm{p}<0.001 ; 7.0$ versus 6.7\%, $\mathrm{p}<0.001$, respectively). Overall, HFpEF had a higher proportion of Medicare as the primary expected payor (80.7\% versus $71.9 \%, p<0.001$ ), while Medicaid and private insurance had higher proportions of HFrEF cases
(8.7\% versus $5.6 \%, \mathrm{p}<0.001 ; 13.5 \%$ versus $10.3 \%$, $\mathrm{p}<0.001$, respectively).

Proportions of Elixhauser comorbidities were different between both groups, with HFpEF having a higher proportion of deficiency anaemias, chronic pulmonary disease, diabetes, obesity, and renal failure.

There was a slightly higher length of stay for patients with HFrEF $(5.43 \pm 5.87$ versus $5.37 \pm 5.09$ days, $p<0.001$ ), and a higher overall cost for patients with HFrEF. HFrEF had a higher tendency for routine disposition and short-term hospitalisations, whereas patients with HFpEF were more likely to be transferred to a SNF or HHC. The inpatient mortality rate was higher for HFrEF than HFpEF (2.8\% versus $2.5 \%, p<0.001)$.

\section{Heart failure with reduced ejection fraction versus heart failure with preserved ejection fraction: post-Hospital Readmissions Reduction Program}

During 2014-15, HFpEF had higher representation in the inpatient sample compared to HFrEF.

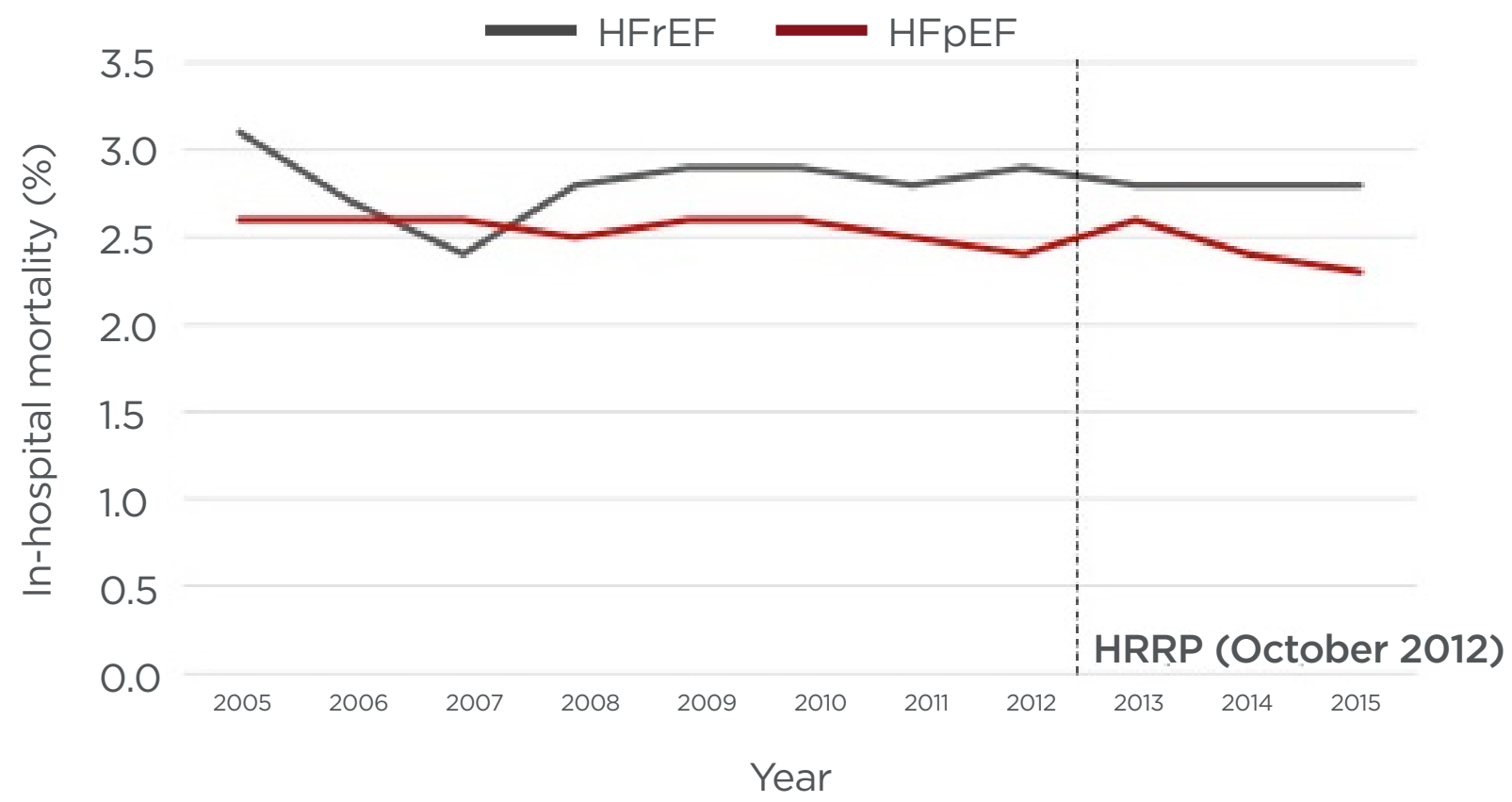

Figure 2: In-hospital mortality before and after implementation of the Hospital Readmissions Reduction Program (HRRP).

HFpEF: heart failure with preserved ejection fraction; HFrEF: heart failure with reduced ejection fraction; HRRP: Hospital Readmissions Reduction Program. 
Average age, female proportion, and proportion of Elixhauser comorbidities, as stated previously, were still higher in the HFpEF sample. HFrEF continued to have a higher mortality rate, higher cost, and higher length of stay. Figure 2 displays the inpatient mortality trends on a year-by-year basis.

\section{DISCUSSION}

The HRRP was billed as a unifying policy targeting the reduction of excess readmissions, determined by a ratio of expected risk-adjusted 30-day readmission rates (excess reductions ratio: $>1$ ), in six major categories including heart failure. Subsequent analyses reinforce the notion that real-world HRRP execution has reduced readmissions by negligible amounts. ${ }^{19,20}$ More critical studies posit that HRRP has been a net loss with regard to the societal cost of enforcement, given that 'safety net' hospitals are disproportionately penalised and resources that could have potentially been funnelled into programmes aimed at improving outcomes such as mortality have instead been redirected into efforts to reduce readmissions and avoid penalisation. ${ }^{21,22}$

The results support prior observations that any reduction in readmissions for $\mathrm{HF}$ has been minimal. Although mortality rates derived from NIS data are inherently limited to inpatient deaths, trends in inpatient mortality can serve as loose and indirect measures of the evolution of disease severity as hospitals are incentivised to reduce admissions and treat healthier patients in the emergency department or observation units, reserving inpatient status for patients who are sicker..$^{9,23}$ This analysis did not reveal a difference in mortality for patients with HFrEF. Notably, mortality for patients with HFpEF declined in a statistically significant manner following HRRP implementation.

Prior studies have attempted to delineate trends in mortality and readmissions in $\mathrm{HF}$ as a global entity after HRRP implementation but, to date, no analysis exists for the HF subtypes. Overall, readmissions decreased slightly after HRRP implementation for both subtypes (HFrEF: 22.321.2\%; HFpEF: 22.4-21.2\%). HFpEF mortality rates decreased (2.5-2.4\%), while HFrEF inpatient mortality rates remained static (2.8\%). For both time periods, HFrEF exhibited higher inpatient mortality rates when compared with HFpEF.

Following HRRP, patients with HFrEF were discharged to short-term hospitals or home with $\mathrm{HHC}$ more frequently, while patients with HFpEF were discharged to SNF more often. The readmission cost for HFrEF increased postHRRP, relative to the cost pre-HRRP. Compared to HFpEF, HFrEF admissions and readmissions were more expensive both before and after HRRP implementation. There was also a shift in the proportion of patients to teaching hospitals in the post-HRRP era in both HF subtypes.

The increased utilisation of short-term hospitals, $\mathrm{HHC}$, and SNF perhaps represents efforts to decrease readmissions via transitory healthcare institutions. It is not immediately clear if these efforts have translated into lower readmission rates, but studies evaluating differences in discharge disposition trends between high and low readmission centres have not demonstrated any significant correlation. ${ }^{10}$ This suggests that, given the higher costs, hospitals could aim to target HFrEF readmissions.

Among the elderly, HF remains the most common cause for both hospitalisations and readmissions. ${ }^{24}$ When compared with the other disease targets of HRRP, HF is the leading driver of the readmissions penalty, highlighting the potential impact of and necessity of strategies aimed at improving quality care for patients with $\mathrm{HF}^{2}$ In the first year of HRRP alone (fiscal year 2013), 64\% of participating centres were penalised to the tune of 290 million USD, prompting hospitals to invest resources into reducing readmissions. ${ }^{10}$ An analysis found that the steepest decline in readmission rates following the passage of the HRRP coincided with changes in the electronic transaction standards used by hospitals to submit Medicare claims, allowing an increase from 9-10 to 25 diagnosis codes, resulting in increased patient risk scores and subsequently 'lower' risk-adjusted readmission rates. ${ }^{19}$ A similar study utilised the NRD to replicate risk-adjusted readmission rates and found readmission rates decreased following the implementation of HRRP. The decline was much more modest than that reported by Centers for Medicare \& Medicaid Services (CMS), 
likely due to the change in electronic transaction standards, and readmission rates of Medicaid patients were consistently higher than those of Medicare beneficiaries..$^{25-27}$

The overall lack of HF readmissions reduction cannot be blamed on HRRP or policy alone, as this is a well-documented problem. A meta-analysis identified multiple effective strategies (e.g., post-discharge communications, supervised exercise programmes, and dietary interventions) were marginally beneficial individually, but combinations of interventions doubled the probability of avoiding readmission. ${ }^{4}$ A cross-sectional study evaluating the effects of readmission reduction strategies in patients with HF at 599 hospitals enrolled in nationwide readmission reduction programmes identified six effective interventions, though $<30 \%$ of hospitals employed the measures and only $7 \%$ of hospitals enacted all six strategies. ${ }^{28}$ Though evidence-guided strategies to reduce HF readmissions exist, they are often hampered by either minimal efficacy or inconsistent application on the part of the patient.

Similarly, multiple investigations have found that the transition from inpatient to outpatient care can cause problems, as more than half of patients are unaware of medication changes at discharge, with nearly $25 \%$ of these changes likely made in error, due to incomplete medication reconciliation. ${ }^{29}$ With results suggesting a shift in eventual disposition, proper reconciliation may be critical for successful patient outcomes. The multi-centre HF-ACTION trial, consisting of 2,331 patients across 82 centres, found that patient adherence to prescribed home exercise programmes over a median of $\mathbf{3 0}$ months was approximately $30 \% .{ }^{30}$ Attendance at outpatient cardiac rehabilitation programmes seems to be particularly poor among the Medicare population. ${ }^{31}$ This combination of patient and hospital factors resisting adoption of the limited number of proven methods to reduce HF readmissions forms a barrier to progress that no single policy can remedy. Regardless, the results underscore the notion that the HRRP, despite and perhaps partly due to the aforementioned challenges in its place, has been unsuccessful in reducing readmissions for the HF population.

Further studies stratifying by payor may prove enlightening. Using the entirety of Medicare inpatient claims from 2009, Gu et al. ${ }^{32}$ created a sample population using Medicare's inclusion and exclusion criteria for readmission measures, and using dual Medicare and Medicaid eligibility as a surrogate for low socioeconomic status, they found that readmission rates for dual-eligible patients were significantly higher across the conditions targeted by the HRRP when compared with Medicare beneficiaries alone, with a HF readmission rate of $27.2 \%$ in dual-eligible patients versus $23.9 \%$ in non-dual-eligible patients. Applying this same methodology to both mortality and readmissions may uncover disparities with regard to downstream consequences of a push away from admitting patients.

\section{LIMITATIONS}

This analysis has several limitations. Namely, this is a retrospective and observational analysis. Additionally, this study utilised two databases, the NRD and NIS, and extracted data from both using ICD-9 codes, raising the possibility of inadequate capture of patients and potential misclassification of patients. These databases do not contain clinical variables, so it was not possible to objectively confirm whether patients had true systolic versus diastolic dysfunction. All insurance types were included in this analysis, though the HRRP targets Medicare recipients aged 65 years or older. However, the inclusion of all payors allowed for a more robust commentary regarding the efficacy of the programme in achieving its underlying intent to reduce readmission rates at large. 


\section{References}

1. Centers for Medicare \& Medicaid Services (CMS). Hospital ReadmissionsReduction-Program (HRRP). 2019. Available at: https://www.cms.gov/ Medicare/Medicare-Fee-for-ServicePayment/AcutelnpatientPPS/ Readmissions-Reduction-Program. Last accessed: 5 May 2019.

2. Vidic A et al. Heart failure is a major contributor to hospital readmission penalties. J Card Fail. 2015;21(2):134-7.

3. Rahimi K et al. Risk prediction in patients with heart failure: a systematic review and analysis. JACC Hear Fail. 2014;2(5):440-6.

4. Wan TTH et al. Strategies to modify the risk of heart failure readmission: a systematic review and meta-analysis. Health Serv Res Manag Epidemiol. 2017;4:2333392817701050.

5. Desai NR et al. Association between hospital penalty status under the hospital readmission reduction program and readmission rates for target and nontarget conditions. JAMA. 2016;316(24):2647-56

6. Zuckerman RB et al. Effect of a hospital-wide measure on the readmissions reduction program. $\mathrm{N}$ Engl J Med. 2017;377(16):1551-8.

7. Khera $\mathrm{R}$ et al. Association of the hospital readmissions reduction program with mortality during and after hospitalization for acute myocardia infarction, heart failure, and pneumonia. JAMA Netw Open. 2018;1(5):e182777.

8. Gupta A et al. Association of the hospital readmissions reduction program implementation with readmission and mortality outcomes in heart failure. JAMA Cardiol. 2018;3(1):44-53.

9. Krumholz HM et al. Relationship between hospital readmission and mortality rates for patients hospitalized with acute myocardial infarction, heart failure, or pneumonia. JAMA. 2013;309(6):587-93.

10. Pandey A et al. Association of 30-day readmission metric for heart failure under the hospital readmissions reduction program with quality of care and outcomes. JACC Heart Fail. 2016;4(12):935-46.

11. Heidenreich PA et al. Divergent trends in survival and readmission following a hospitalization for heart failure in the veterans affairs health care system 2002 to 2006 . J Am Coll Cardiol. 2010:56(5):362-8.

12. Lekavich $\mathrm{CL}$ et al. Heart failure preserved ejection fraction (HFpEF): an integrated and strategic review. Heart Fail Rev. 2015;20(6):643-53

13. Steinberg BA et al. Trends in patients hospitalized with heart failure and preserved left ventricular ejection fraction: prevalence, therapies, and outcomes. Circulation. 2012;126(1):65-75

14. Bhatia RS et al. Outcome of heart failure with preserved ejection fraction in a populationbased study. N Engl J Med. 2006;355(3):260-9.

15. Owan TE et al. Trends in prevalence and outcome of heart failure with preserved ejection fraction. 2006;355(3):251-9.

16. Burkhoff D. Mortality in heart failure with preserved ejection fraction: an unacceptably high rate. Eur Heart J. 2012;33(14):1718-20.

17. Shah $\mathrm{KS}$ et al. Heart failure with preserved, borderline, and reduced ejection fraction: 5-year outcomes. J Am Coll Cardiol. 2017;70(20):2476-86.

18. Borlaug BA, Paulus WJ. Heart failure with preserved ejection fraction: pathophysiology, diagnosis, and treatment. Eur Heart J. 2011;32(6):670-9.

19. Ody $\mathrm{C}$ et al. Decreases in readmissions credited to Medicare's program to reduce hospital readmissions have been overstated. Health Aff (Millwood). 2019;38(1):36-43.

20. Ibrahim AM et al. Association of coded severity with readmission reduction after the hospital readmissions reduction program. JAMA Intern Med. 2018;178(2):290-2.

21. Thompson MP et al. Most hospitals received annual penalties for excess readmissions, but some fared better than others. Health Aff (Millwood). 2017;36(5):893-901.

22. Carey K, Lin MY. Hospital readmissions reduction program: safety-net hospitals show mprovement, modifications to penalty formula still needed. Health Aff (Millwood). 2016;35(10):1918-23.

23. Medicare and the Health Care Delivery System. 2018. Available at: www.medpac.gov. Last accessed: 17 September 2019

24. Chen $\mathrm{J}$ et al. National and regional trends in heart failure hospitalization and mortality rates for Medicare beneficiaries, 1998-2008. JAMA 2011;306(15):1669.

25. Cox ZL et al. Centers for Medicare and Medicaid Services' readmission reports inaccurately describe an institution's decompensated heart failure admissions. Clin Cardiol. 2017;40(9):620-5.

26. Wadhera RK et al. Association of the hospital readmissions reduction program with mortality among Medicare beneficiaries hospitalized for heart failure, acute myocardial infarction, and pneumonia. JAMA 2018:320(24):2542-52.

27. Ferro EG et al. Patient readmission rates for all insurance types after implementation of the hospital readmissions reduction program. Health Aff (Millwood). 2019;38(4):585-93.

28. Bradley EH et al. Hospital strategies associated with 30-day readmission rates for patients with heart failure. Circ Cardiovasc Qual Outcomes. 2013;6(4):444-50.

29. Ziaeian B, Fonarow GC. The prevention of hospital readmissions in heart failure. Prog Cardiovasc Dis. 2016;58(4):379-85.

30. O'Connor CM et al: HF-ACTION Investigators. Efficacy and safety of exercise training in patients with chronic heart failure HF-ACTION randomized controlled trial. JAMA 2009;301(14):1439-50.

31. Fleg JL. Preventing readmission after hospitalization for acute heart failure: a quest incompletely fulfilled. JACC Heart Fail. 2018;6(2):153-5.

32. Gu $Q$ et al. The Medicare hospita readmissions reduction program: potential unintended consequences for hospitals serving vulnerable populations. Health Serv Res. 2014:49(3):818-37. 